\title{
El sistema inter-capital: hacia una mundialización ampliada de la economía capitalista
}

\author{
Esteban Torres \\ Universidad Nacional de Córdoba, CONICET (UNC-CONICET) \\ esteban.tc@conicet.gov.ar \\ https://orcid.org/0000-0002-6040-562X
}

\author{
How to cite this paper: \\ Torres, Esteban (2020). El sistema inter-capital: hacia \\ una mundialización ampliada de la economía capitalista. \\ Revista Encuentros, Universidad Autónoma del Caribe. Vol. 18- \\ 3. Dossier. \\ Doi: 10.15665/encuent.v18i3.2331
}

Recibido: 06 de octubre de 2019 / Aceptado: 10 de diciembre de 2019

\section{RESUMEN}

En el presente artículo me propongo avanzar de forma metódica en el desarrollo de una nueva perspectiva del capitalismo, atenta a la especificidad de América Latina, que se materializa en el concepto de sistema inter-capital. Para ello someto tal categoría a un análisis comparativo con una de las visiones críticas del capitalismo más vigorosas de la actualidad: la teoría del Landnahme capitalista del sociólogo alemán Klaus Dörre. El trabajo focaliza su atención en dos aspectos elementales: i) la conceptualización general de la dinámica capitalista, y ii) la concepción del espacio que acompaña a la primera. Entre otras cuestiones, el trabajo demuestra como la perspectiva del sistema inter-capital permite ensanchar el marco de conocimiento social sobre los actuales procesos de mundialización económica a partir de reconocer el funcionamiento histórico de un mecanismo de doble estructuración de clases en el sistema capitalista moderno.

Palabras clave: teorías del capitalismo, doble estructuración, clases sociales, América Latina, procesos de cambio social.

\section{The Inter-Capital System: Towards an Expanded Mundialization of the Capitalist Economy}

\begin{abstract}
In this article I propose to advance in the development of a new perspective of capitalism, attentive to the specificity of Latin America, which materializes in the concept of inter-capital system. To this end, I submit such a category to a comparative analysis with one of the most vigorous critical visions of capitalism today: the capitalist Landnahme theory of the German sociologist Klaus Dörre. The work focuses its attention on two elementary aspects: i) the general conceptualization of capitalist dynamics, and ii) the conception of space that accompanies the first. Among other questions, the work demonstrates how the perspective of the inter-capital system allows widening the framework of social knowledge on the current processes of economic globalization from recognizing the historical functioning of a mechanism of double structuring of classes in the modern capitalist system.
\end{abstract}

Key Words: Capitalist Theories, Double Structuring, Social Classes, Latin America, Processes of Social Change. 


\section{INTRODUCCIÓN}

En el presente trabajo me propongo avanzar de forma metódica en el desarrollo de una nueva perspectiva del capitalismo edificada en dialogo con el marxismo pero que rechaza ser clasificada como marxista, neomarxista o pos-marxista. Esta visión se materializa en el concepto de sistema inter-capital. Se trata del núcleo económico de una teoría del cambio social mundial atenta a la especificidad de América Latina, a la que denomino teoría del juego de apropiación mundial. Para la realización de dicho propósito someto el concepto de sistema inter-capital a un análisis comparativo con una de las teorías críticas del capitalismo más vigorosas de la actualidad. Me refiero a la teoría del Landnahme capitalista que desarrolla el sociólogo alemán Klaus Dörre ${ }^{1}$. La analítica comparativa entre la teoría del Landnahme y la perspectiva del sistema inter-capital apunta al esclarecimiento de tres aspectos elementales: i) la conceptualización general de la dinámica capitalista, y ii) la concepción del espacio elaborada en relación con la primera. La secuencia comparativa se inicia para cada uno de los puntos con el análisis sintético del sistema de Dörre, por ser este un cuerpo de ideas ya consagrado en la sociología contemporánea. Pese a contraponer dos perspectivas teóricas, el análisis comparativo recurre a un movimiento de tránsito permanente entre lo abstracto y lo concreto. En cualquier caso, el cuadro de relaciones ofrecido no busca la formalización de registros exhaustivos sino la aproximación comparada a las coordenadas generales de ambas visiones. Entre otros aspectos, el presente artículo demuestra como la perspectiva del sistema inter-capital permite ensanchar y rectificar el campo de conocimiento sociológico sobre los actuales procesos de mundialización económica a partir de reconocer la especificidad capitalista de América Latina en el juego de apropiación mundial.

\section{El Landnahme capitalista y el sistema inter-capital}

La comparación entre la teoría del capitalismo de Klaus Dörre y la visión del sistema inter-capital -ésta última

1 Se trata del referente central de la Escuela de Jena y uno de los tanques intelectuales de la izquierda alemana en la actualidad. Junto a ello, Dörre es director de la revista Global Dialogue de la Asociación Internacional de Sociología (ISA), así como de la prestigiosa Berliner Journal für Soziologie. en proceso de formulación- abre puntos de observación claves respecto al modo en que la teoría social moderna, y el marxismo en particular, se vienen ocupando de analizar los procesos de cambio económico. Aquí me ocuparé de presentar los trazos generales de ambas perspectivas para luego extraer algunas conclusiones de ello.

La teoría del Landnahme capitalista es el dispositivo sociológico que desarrolla Klaus Dörre para explicar el devenir del capitalismo contemporáneo. Según éste, el concepto "Landnahme capitalista" lo propone inicialmente Burkart Lutz, un referente central de la sociología industrial alemana, apoyándose en el trabajo de Rosa Luxemburgo. Los mismos pasos de Lutz seguiría Dörre al convertir a la intelectual polaca en la fuente teórica principal para poner a punto su perspectiva marxista. El sociólogo alemán reconocerá que la noción de "Landnahme" no tiene una traducción exacta al inglés ni al español, aunque el término que más se le asemeja sería el de "expropiación". De este modo, y como luego veremos con más precisión, la perspectiva de Dörre se podría concebir como una teoría de la expansión capitalista basada en la infinita expropiación de lo nocapitalista. El Landnahme capitalista seguiría una compulsión sistémica expansiva que tiende a aumentar constantemente el número de vidas humanas, incluidas las de los capitalistas, que se encuentran sometidas a los imperativos del mercado. Para el autor estos imperativos se refieren a una racionalidad basada en los principios de competitividad y de maximización de ganancias. En el núcleo del concepto de Landnahme reside la idea de que el capitalismo, basado en la generalización de la forma mercancía, nunca se puede reproducir apelando a una lógica interna de alimentación. El sociólogo dirá que para la realización de su movimiento expansivo el capitalismo es estructuralmente dependiente de un Otro no capitalista. De este modo, el desarrollo capitalista se despliega como un complejo movimiento de apropiación de la exterioridad no capitalista y de generación de nuevas exterioridades nocapitalistas que, llegada la circunstancia, pueden ser nuevamente expropiadas. El Landnahme opera entonces a partir de una dinámica interna/externa, exhibiendo una estructura dual. El capitalismo, ya sea en su modalidad industrial o financierizada, adquiere para Dörre la forma de un metabolismo de recreación permanente entre los mercados capitalistas internos 
y los mercados externos no mercantilizados (o aún no plenamente mercantilizados). La expansión del sistema económico ocurriría en el espacio y en el tiempo y se desarrollaría tanto hacia adentro como hacia afuera de las sociedades nacionales o de los mercados capitalistas nacionales. En cualquier caso, para Dörre se trata de una fuerza de propulsión lo suficientemente arrolladora como para expandirse sobre toda la sociedad. Para Dörre el mundo se presenta como la sumatoria de territorios internos ya apropiados por la expansividad capitalistas y de territorios a la vez nuevos y externos en condiciones de ser conquistados por el mismo movimiento histórico de expropiación capitalista. La idea de tierras externas y nuevas por conquistar remite directamente al léxico que emplea Rosa Luxemburgo para referirse al proceso de expansión colonial que se expande hacia la periferia desde mediados del siglo XIX hasta la primera guerra mundial (Luxemburgo, 1913). Si bien Dörre suele emplear comillas para referirse tanto a lo externo como a lo nuevo, ello no necesariamente desmantela el espacio geográfico originario de la expansión colonialista a la que alude Luxemburgo, fuertemente marcado por la lentitud de los traslados marítimos, así como por el horizonte de expectativas de conquista de lo completamente otro, de lo completamente inesperado y/o de lo completamente inferior. Dörre busca desprenderse del lastre geográfico y extra-europeo que acompaña la idea de tierras nuevas y externas indicando, por ejemplo, que esta "nueva tierra" debe entender más bien como la mercantilización de los recursos naturales, territorios, sectores, actividades y estilos de vida que antes no lo estaban, o bien que no lo estaban totalmente ${ }^{2}$. En cualquier caso, dejando de lado esta cuestión, la visión de la externalidad capitalista de Dörre se apoya según mi lectura sobre tres premisas básicas: i) la externalidad capitalista se manifiesta en todas las sociedades del sistema mundo; ii) en las economías periféricas del sistema-mundo predomina la territorialidad externa; iii) en las sociedades del Centro los individuos no integrados al mercado de trabajo asalariado serían parte de la externalidad capitalista. En el próximo apartado analizaré estos aspectos con mayor detenimiento.

Desde la teoría del juego de apropiación mundial, el mundo capitalista contemporáneo se define como un

2 Para esta reconstrucción sintética de la noción de Landnahme se emplearon como referencia Dörre, 2012, 2014, 2016a, 2016b, 2018 y 2019. sistema inter-capital. El sistema inter-capital (SI) es un sistema de apropiación capitalista mundial que, al igual que el Landnahme de Dörre, se configura a una partir de una estructura dual. Pero, a diferencia de éste último, no es un primera instancia una dualidad global entre lo capitalista y lo no capitalista sino entre lo capitalista dominante y lo capitalista subalterno. La dominación y la subalternización capitalista se definen en un plano global a partir de una relación centro-periferia ${ }^{3}$. Desde la óptica de la TJA, al igual que en la visión de Dörre, la apropiación capitalista es una apropiación de clase, si bien para la primera la clase no es una unidad de acción colectiva en-sí ni para-sí. Distanciándose del esencialismo marxista, la TJA establece una diferenciación entre clase y actor. Para el SI la unidad de acción colectiva no es la clase sino la organización, siendo toda organización una organización de clases. Los sindicatos, los partidos políticos, los movimientos sociales, los Estados, las cámaras empresariales, las pequeñas y medianas empresas (PYMES) o las grandes empresas tecnológicas como Google son todas organizaciones. Desde esta visión todo actor individual y social expresa una unidad de acción de clase, y por lo tanto adopta la forma de un actor-clase, pero no toda clase deviene necesariamente en actor colectivo. En cualquier caso, en relación con la visión de Dörre, la noción de clase social cambia principalmente en un doble sentido: adopta una forma más abarcativa y a su vez adquiere una acepción distinta. Si para el marxismo en general y para la sociología de Dörre en particular la relación de clase se define a partir de una ecuación de fuerzas entre la clase capitalista y la clase trabajadora, desde la SI se concibe una estructura doble de relaciones de clases. De este modo se distingue entre relaciones de clases moleculares y relaciones de clases orgánicas. Las relaciones de clases moleculares son las encargadas de procesar en nuevos términos las relaciones de clases marxiana. Lo que define la pertenencia del individuo a una clase social molecular no es su inscripción material en algunas de las posiciones enfrentadas en las relaciones de producción, sino su fuente principal de ingresos. Para definir la posición del individuo en la clase

3 Los antecedentes teóricos contemporáneos de la relación centro-periferia que reelabora el SI se asocian principalmente con los trabajos de Darcy Ribeiro, Raúl Prebisch, Fernando Henrique Cardoso y Enzo Faletto (Ver Ribeiro, 1968; Prebisch, 1976 y 1985; Cardoso, 1965; Cardoso y Faletto, 1973; Ribeiro, 1968). Para una reconstrucción sistemática e histórica de tales antecedentes, consultar Torres y Borrastero, 2019. 
molecular hay que atender a su estructura y su volumen de ingresos ${ }^{4}$. En vez de definir dos clases elementales en relación de oposición, el SI define cuatro clases moleculares en situación de enlace y de enfrentamiento real y potencial: la clase dependiente del beneficio, la clase dependiente del salario, la clase dependiente de la caridad y la clase dependiente del delito 5 . Desde esta composición molecular, la clase capitalista se resignifica como clase dependiente del beneficio, mientras que la clase trabajadora se redefine como clase dependiente del salario. Como se puede observar, para estas dos clases moleculares adopto el léxico de Wolfgang Streeck (Streeck, 2013). El tipo restante de relación de clases, la relación de clases orgánicas, traslada el locus dinámico a la relación de apropiación global. A diferencia de la clase molecular, la clase orgánica es el entramado nacional de clases moleculares. Una clase orgánica sería en cierta medida equivalente a un sistema nacional de economía ${ }^{6}$. Desde el esquema que ofrece el SI se distinguen tres tipos de clases orgánicas: la clase dependiente de la materia prima, la clase dependiente de la industria y la clase dependiente del conocimiento ${ }^{7}$. El modo en que se desenvuelve la lucha de apropiación global entre clases orgánicas determina la pertenencia de cada una al estrato central o bien al estrato periférico. Aquella clase orgánica ubicada en el estrato periférico puede definirse como una clase orgánica periférica. Del mismo modo ocurre con la pertenencia al estrato central. De este modo, la relación de clases orgánicas se define en su forma paradigmática como la relación entre clases orgánicas centrales y clases orgánica periféricas. Este ordenamiento, a su vez, me permite distinguir al menos dos entramados económicos que componen el sistema inter-capital: el entramado económico nacional y el entramado económico global. El primero estaría compuesto por una red de clases moleculares y el segundo por una red de clases orgánicas. A tal esquema se agrega una tercera estructuración reticular: el entramado económico regional. Este último estaría conformado por

4 Para un desarrollo de la diferencia entre la pertenencia de clase marxiana y la pertenencia de clase molecular, ver Torres, 2019.

5 La tipología de las clases moleculares se desarrolla en Torres, 2019.

6 Tal idea de sistema nacional de economía guarda parecidos de familia con la demarcación teórica ofrecida por el economista alemán Fredrich List (ver List, 1841).

7 Se puede consultar un primer desarrollo teórico de la estructura de clases orgánicas en Torres, 2019. una red de clases orgánicas periféricas o por una red de clases orgánicas céntricas, estableciéndose a su vez el interior de cada red regional un conjunto de posiciones de clases centrales y periféricas. El sistema inter-capital como sistema mundial se conforma a partir de vínculos irreductibles y de inmanencia entre las múltiples entramados nacionales, más o menos integrados regionalmente, y el entramado global. La expansión y la retracción entre lo capitalista y lo no capitalista, en los términos de Dörre, se desenvolvería exclusivamente en el SI al interior de los entramados económicos nacionales, mientras que el entramado económico global se definiría en la actualidad a partir de un proceso de expansión y de retracción entre clases orgánicas céntricas y periféricas. Estas clases orgánicas son todas capitalistas aunque capitalistas de un modo estructuralmente diferente entre sí. Hago referencia a un sistema inter-capitalista y no a un sistema capitalista a secas precisamente porque el sistema de apropiación económico mundial se configura centralmente a partir de intensas batallas de apropiación entre régimenes capitalistas y no a partir de las fuerzas de apropiación operantes al interior de un sistema capitalista homogéneo, constituido en el Centro Global, luego auto-propulsado hacia la periferia y finalmente direccionado hacia su necesaria desintegración.

La idea de un sistema de apropiación intercapitalista que evoluciona a partir de un proceso continuo de clasificación, reclasificación y desclasificación orgánica y molecular permite superar los dos reduccionismos centrales que marcaron el viejo campo de discusión del progresismo global a partir de la mundialización del movimiento de descolonización a mediados del siglo XX. El primero es el reduccionismo clasista del marxismo eurocéntrico, que considera quela contradicción principal que resultaba necesario superar era una contradicción de clase focalizada en los territorios nacionales del Norte, y que los problemas derivados del colonialismo y de la división internacional del trabajo llegarían a su fin tras el derrocamiento del capitalismo y la conquista del poder por el proletariado en los países avanzados. Desde esta visión se asumía que hasta tanto se lograse sepultar al capitalismo avanzado, no resulta inaceptable promover un colonialismo proletario o socialista en la periferia global $^{8}$. El segundo reduccionismo operó en una dirección

8 Una de las posiciones indulgentes más reconocidas respecto a un colonialismo de izquierdas fue la que asumió Kautsky. Este propuso distinguir 
contraria: estableció una diferenciación entre nación y clase, o entre nación, clase y raza, para indicar que el motor central que dinamiza las sociedades de la periferia global es la contradicción entre naciones dominantes y naciones dominadas y que, por lo tanto, la política de clases debía desactivarse en buena medida a favor de una política de expansión nacionalista anti-imperialista ${ }^{9}$. La idea de un sistema intercapital compuesto por una red interconectada de relaciones entre clases orgánicas y clases moleculares desactiva el divisionismo entre nación y clase para restituir a la nación como clase relacional en el plano global, articulada al movimiento reticular entre clases al interior de los planos nacionales central y periférico. Cuando afirmo que la evolución del capitalismo como proceso intercapital permite concebir a la economía mundial a partir de un principio de diferenciación de clases a la vez global y nacional, estoy reconociendo que no se puede pensar que la estructura de clases moleculares en la periferia podría adquirir la misma forma que la estructura de clases moleculares en el Centro Global. La composición interna de una clase orgánica dependiente de la materia prima, del modo en que se constituye actualmente en América Latina, difiere estructuralmente de la dinámica de clases moleculares correspondiente a un bloque orgánico europeo dependiente de la industria. Antes de hablar de una clase molecular periférica o de una clase molecular céntrica, lo que conllevaría cierto determinismo orgánico, correspondería concebir a toda clase molecular como clase molecular en la clase orgánica céntrica o periférica. El sistema de apropiación intercapital permite concebir la llamada "división internacional del trabajo" como una división de clases y no como una división durkheimniana de funciones que descentra una analítica de clases para la comprensión de los procesos de cambio social mundiales. Desde la óptica del SI se puede asumir que si la "división del trabajo internacional" se constituye en una manifestación histórica de la división de clases orgánicas, la "división del trabajo nacional" es una forma de organización emergente de la división de clases moleculares. El sistema inter-capitalista se convierte entonces en un concepto que permite exhibir la interdependencia entre una economía política del "trabajo" internacional y una economía política del

entre "colonia de trabajo" y "colonia de explotación” (ver Kautsky, 1907).

9 Ver Balibar y Wallerstein, 1988; Amin, 1979. "trabajo" nacional. Si para la visión marxista de Dörre las dos economías que dirimen el futuro económico del mundo son la economía política del trabajo y la economía política del capital (Dörre, 2012, 2014, 2016a), para la SI dichas economías deben contemplarse en conexión con un segundo ámbito de estructuración: el que se establece entre la economía política de los entramados nacionales del Centro y la economía política de los entramados nacionales del Sur Global. De este modo, si la teoría marxiana del capitalismo se define a partir de una estructuración simple de clases, la teoría del intercapitalismo lo hace a partir de la doble estructuración mencionada.

El inter-capitalismo como doble estructuración económica, conformado a partir de la competencia y la cooperación friccionada entre capitalismos agrarios, industriales y cognitivos, conlleva una transformación radical en el modo de concebir las clases sociales que interaccionan en el campo de luchas sociales. Si para la teoría del Landnahme capitalista las clases subalternas son las clases trabajadoras, desde la visión del SI las clases subalternas son las clases moleculares de bajos ingresos que se reproducen tanto en el Centro como en la periferia Global, así como clases orgánicas periféricas, que representan el conjunto de clases moleculares en el entramado nacional periférico. Las clases moleculares de bajos ingresos se componen a partir del estrato inferior de la clase dependiente del salario, del estrato inferior de las clases dependientes del beneficio y del delito, así como de la clase dependiente de la caridad en su conjunto ${ }^{10}$.

Finalmente, la perspectiva del juego de apropiación mundial, incluyendo la teoría del sistema intercapital, reclama para sí la recreación de una dialéctica social de apropiación. Recurre a una lógica dialéctica para intentar explicar el movimiento de la sociedad mundial, considerando y a la vez trascendiendo una racionalidad y una dimensión económica. Desde el sistema intercapital la dinámica económica se concibe a partir de un movimiento de clasificación orgánica y molecular que activa dinámicas verticales y horizontales, en procesos de permanente expansión y retracción. Para el caso de la clasificación vertical, tal retracción y expansión pueden concebirse como procesos de clasificación ascendentes

10 Consultar el diagrama general de clases moleculares en Torres, 2019. 
(reclasificación) y descendentes (desclasificación). Dicho movimiento contrasta con el Landnahme capitalista de Dörre, el cual opera a partir de una lógica más bien unidireccional de expansión sobre lo no capitalista interno y externo. A este último, al despliegue externo, el autor lo concibe como una expansión económica unidireccional del centro sobre las periferias. La dinámica de apropiación de Dörre no contemplaría entonces un momento de retracción de lo capitalista con posibilidades de forzar reprogramaciones no deseadas de los actores sociales dominantes. Desde las coordenadas del SI se echa de menos en la visión del sociólogo alemán la consideración de una lógica de retracción capitalista general, así como de una lógica de retracción capitalista céntrica. De este modo, pareciera que el peso que le adjudica Dörre al polo expansionista, tanto hacia adentro de las sociedades nacionales europeas como hacia afuera, conlleva al menos un doble riesgo: i) el de desactivar una lógica dialéctica que el propio autor señala como su lógica de referencia; ii) el de contradecir alguno de los hechos centrales señalados por su propia explicación sociológica del movimiento expansivo. Respecto a la segunda cuestión, no resulta sencillo compatibilizar la lógica de creciente expansión de lo capitalista de Dörre con su reconocimiento explícito de la expansión cuantitativa de la sociedad excluida del mercado del trabajo asalariado (fracción de sociedad que el autor caracteriza como no-capitalista), así como con el eventual incremento de la intervención no capitalista del Estado. En principio, lo que permitiría a Dörre adjudicar características no capitalistas a tales ámbitos desde la tesis de una creciente expansión-expropiación capitalista, es un principio de funcionalidad capitalista de lo no capitalista. En mi lectura, ambos territorios se presentan para el autor como espacios funcionales a la expansión capitalista. El primero lo hace principalmente a partir de la función marxiana de "ejercito de reserva" y el segundo a partir de una función de reproducción estatal del capital poco nítida. Desde la perspectiva de la SI, en cambio, no se puede hablar de una potencia capitalista en plena expansión si el potencial de integración económica del capitalismo se reduce, tal como lo reconoce Dörre. La des-integración económica y social del capitalismo se correspondería con una instancia de retracción de su poder de apropiación del mundo, y no lo contrario. De este modo, según la óptica del sistema de apropiación inter-capitalista la dinámica económica va constituyendo un campo a partir de un proceso a la vez en expansión y en retracción selectiva.

\section{La diferenciación espacial de la dinámi- ca capitalista: espacios internos, espacios externos y espacios subalternos.}

La teoría del Landnahme y la visión del sistema intercapital habilitan dos formas diferentes y parcialmente complementarias de concebir la dimensión espacial de la dinámica capitalista. Para la primera el funcionamiento del sistema capitalista se explica en primera instancia a partir de una estructura y un movimiento espacial dualista. A su vez, el espacio para Dörre se define como un territorio. Tal como señalé, el dualismo espacial imaginado por el autor funciona a partir de la diferenciación entre un territorio interno y externo. En su forma paradigmática el primero es capitalista y el segundo no-capitalista, o mejor dicho, aún-no-capitalista. Complementariamente, aquello que es capitalista puede dejar de serlo para Dörre por obra de las fuerzas expulsivas del propio capitalismo o de las fuerzas integradoras del Estado. Esta ecuación dual se desestabiliza cuando el autor distingue entre un "landnahme interno" que operaría exclusivamente al interior de las sociedades nacionales del Norte Global y un "landnahme externo" que operaría desde tales sociedades hacia y sobre los territorios de la periferia global (Dörre, 2014 y 2016a). De este modo, tendríamos una lógica abstracta y general que opera a partir del movimiento de creación y destrucción permanente de lo interno/externo y dos formas estabilizadas de landnahme concretos, uno interno y otro externo. Un primer interrogante que se presenta aquí es como podría funcionar lo interno capitalista en el landnahme externo, siendo lo externo no capitalista. A falta de precisiones del autor, una respuesta que se podría ensayar es que al impactar el landnahme externo en la periferia global, lo que allí sucede ya no se rige por un movimiento interno/ externo, no al menos homologando la dinámica dual intra-europea. En la teoría del Landnahme pareciera que el devenir capitalista periférico y mundial desde el siglo XX en adelante se explica a partir de la expansión de los centros capitalistas sobre las periferias externas y no capitalistas, integrando de modo accesorio las reacciones posteriores desde el Sur Global para acelerar o para 
impedir su integración forzada al sistema económico mundial. El capitalismo en América Latina aparecería como un territorio de composición indefinida en la exterioridad capitalista del Norte Global, antes que como un espacio-tiempo plenamente moderno con posibilidades de creación e innovación capitalista. Dicho en otros términos, el capitalismo en América Latina se presenta para el autor como efecto del lado externo del capitalismo céntrico o bien como un territorio con algunos ribetes capitalistas pero no del todo conectados en términos causales con el Centro. No hay que perder de vista que el capitalismo para Dörre fija dos operaciones en relación con la exterioridad capitalista: puede y debe utilizar un "afuera" ya existente, y luego puede y necesita producirlo activamente (Dorre, 2012, 2014, 2016a y 2018, 2019). En mi lectura América Latina sería en su mayoría parte de este afuera ya existente, siendo este afuera para Dörre más natural que social.

En cambio, desde el sistema de apropiación inter-capital, la dinámica de exteriorización espacial del capitalismo se diferencia de la primera en dos aspectos fundamentales: i) no fija una relación de exterioridad espacial capitalista entre el centro y la periferia sino una relación interespacial capitalista, siendo la exterioridad capitalista algo que ocurre exclusivamente hacia el interior de cada una de las sociedades nacionales; ii) las exterioridades no capitalistas al interior de las sociedades nacionales, sean éstas del centro o de la periferia, no las crearía el sistema de producción capitalista y cierto accionar estatal sino la combinación entre tal accionar estatal y el sistema de consumo capitalista. Ello significa que buena parte de los espacios y de los agrupamientos de individuos que la teoría del Landnahme ubica en un afuera situacional de los capitalismos nacionales y mundial estarían incluidos en el sistema. Dicho más exactamente, algunas piezas que el esquema de Dörre concibe como afuera el SI lo concibe como un abajo a la vez integrado y diferenciado, dispuesto en mayor o menor medida a la resistencia. Si la primera diferencia habilita el reconocimiento de América Latina como núcleo espacial capitalista diferenciado, a la vez activo y dependiente del Centro Global, la segunda reconoce que los agrupamientos humanos subalternos no dependientes del salario, entre los cuales podríamos incluir el "ejército de reserva" marxiano, no estarían mayoritariamente afuera del sistema capitalista sino integrados como otra clase de un modo más precario y subalterno que el estrato más bajo de la clase dependiente del salario ${ }^{11}$.

De este modo, respecto a la primera diferencia, desde el SI se comprueba que América latina no sería el efecto de la expansión de un Landnahme externo sino un polo completamente integrado en una relación capitalista global, desigual, cambiante y conflictiva. La idea de una inter-espacialidad capitalista puede concebirse igualmente a partir de la idea de un espacio económico mundial compuesto por un entrelazamiento asimétrico e interactivo de espacios económicos naciones y regionales del centro y de la periferia. El registro mundial se amplifica desde el SI desde el momento que agrega a la dinámica global concebida por Dörre las múltiples experiencias de expansión dependiente de la periferia capitalista sobre el Centro desplegadas desde fines de la segunda guerra mundial. Este registro también contempla, necesariamente, las virulentas reacciones de los bloques centrales para impedir la industrialización capitalista de la periferia y de ese modo frenar el proceso de igualación de las condiciones de intercambio capitalista entre el Centro y la periferia Global. A diferencia de los tiempos de las primeras arremetidas colonizadoras, una vez consumado el avance del capitalismo en América Latina bajo dominación inglesa en el siglo XIX, su mercado económico deja de ser externo al mercado capitalista mundial (Mariátegui, 1928; Haya de la Torre, 1935; Scalabrini Ortiz, 1940; Ramos, 1968; Di Tella, 1998; Hobsbawm, 2015). La dinámica económica latinoamericana, con sus movimientos ascendentes y descendentes, así como las características de su inserción global, se explican cada vez menos a partir del viejo hambre colonial de nuevas tierras para la explotación capitalista. Para suponer la persistencia de tales procesos de expropiación en la actualidad habría que reducir drásticamente la observación de los sistemas económicos en América Latina a un conjunto de experiencias cada vez más marginales en relación con la estructura general de las economías nacionales periféricas. En resumidas cuentas, lo que permite indicar el SI es que actualmente no hay un solo

11 Desde la óptica del sistema inter-capitalista las zonas de vulnerabilidad no se crean exclusivamente a partir del proceso de clasificación tradicional, lo que en mis términos sería un proceso de clasificación molecular al interior de las ciudades, sino también y principalmente a partir de un proceso de clasificación orgánica global en el cual las sociedades periféricas del sistema mundo se encuentran al borde de ser caracterizadas en su conjunto como extensos territorios de vulnerabilidad social. 
capitalismo, el capitalismo del centro, que se extiende sobre un espacio periférico aún no capitalista o no del todo capitalista. Desde la óptica del sistema inter-capital las economías periféricas se entienden como espacios diferenciados de operación económica en gran medida supeditados a los Centros. Al reconocer que el sistema capitalista mundial se estructura a partir de un principio de diferenciación espacial entre dos polos capitalistas activos, el SI estaría en condiciones de trascender las formulaciones espaciales unipolares y avanzar en la idea de un modo de desarrollo mundial intrínsecamente intercapitalista. El reconocimiento de la lógica capitalista mundial como una agregación de lógicas capitalistas nacionales en situación de interacción desigual permite igualmente señalar que no habría un único modo ideal de concebir el desarrollo capitalista para el corto y mediano plazo. Cada modo de desarrollo capitalista involucra a la vez un arreglo nacional singular y un modo igualmente singular de integración global. Dicho en otros términos, desde el SI se considera que por una cuestión elemental de condicionamiento estructural global, la planificación económica autonomista desde el Estado latinoamericano tiene que poder imaginar en la actualidad para cada ciclo político presidencial y para un largo plazo el mejor modo de progresión capitalista periférico a partir de un horizonte de expectativas posperiférico. Ello implica, entre otras cuestiones, dejar de importar acríticamente los programas desarrollistas del centro, los cuales se suelen instrumentar en la región sin dimensionar el compromiso intrínseco que los primeros conservan con una división internacional del trabajo que menoscaba las posibilidades de expansión autonomista de la periferia global.

Tal como indiqué, la segunda diferencia entre el Landnahme y el SI del juego de apropiación mundial respecto al modo de concebir la dinámica espacial apunta a la configuración de las sociedades nacionales. Este último comparte con la visión de Dörre que hay un proceso de permanente interiorización y exteriorización capitalista, pero la exterioridad social capitalista sería aquello que eventualmente produce el Estado a partir de sus operaciones de apropiación espacial y sus prestaciones universalistas, así como aquello que está afuera de la sociedad del consumo capitalista. A lo largo y ancho del mundo, los "ejercitos de reserva" de Dörre se encuentran mayoritariamente integrados a la sociedad de consumo capitalista en la forma de una clase dependiente de la caridad y/o de una clase dependiente del delito. Marx fue el primero en reconocer a la mendicidad y al delito como las dos modalidades centrales de ocupación de la sociedad no asalariada (Marx, 1853). La plasticidad con la que Marx emplea el concepto de sub-proletariado creo que expresa esta gran incomodidad respecto a la imposibilidad de excluir al trabajo no asalariado del análisis de las dinámicas económicas capitalistas. Ahora bien, desde el SI no sería la condición de trabajo de las prácticas sociales no asalariadas lo que las integra efectivamente al capitalismo sino su poder de consumo capitalista. De este modo, desde esta óptica, los tres grandes territorios de exterioridad capitalista que se manifiestan de forma no definitiva tanto en el centro como en la periferia serían: a) las formas y las operaciones de apropiación estatales no regidas por un criterio de maximización económica capitalista, b) los espacios geográficos y naturales no capturados ni contemplados para su apropiación por parte de los aparatos empresariales; y finalmente c) la sociedad de individuos descartados, sin posibilidades garantizadas de consumo capitalista y por lo tanto arrojados a la desesperación de la supervivencia física. Dicho esto, desde la SI se asume a modo hipotético que en la actualidad el mundo se está transformando a tal ritmo que las sociedades de la periferia global podrían estar pasando a ser más capitalistas que las sociedades del Centro. Propongo que revisemos esta última hipótesis a partir de desarrollar cada uno de los puntos señalados.

Respecto al primero, tanto el Landnahme como el SI reconocen que el Estado tiene en sentido estricto una capacidad de producción social no capitalista o de desmercantilización capitalista. Aquí evitaré entrar en la discusión respecto a la deseabilidad o no de la necesaria acumulación de poder político que conlleva la construcción de una estatalidad no capitalista. Las únicas dos evidencias que me interesan señalar es que la posibilidad concreta de una realización estatal no capitalista ha dependido históricamente de un poder soberano acumulado en las formas-Estado, y que en ningún momento de la historia mundial los países de América Latina lograron acumular mayor poder de reglamentación estatal soberana que las sociedades nacionales del Centro. Entre tantos aspectos, es posible constatar en la actualidad la existencia de un 
mayor volumen de servicios públicos bajo propiedad y/o gestión estatal en Europa que en América Latina. En resumidas cuentas, la territorialidad exterior y no capitalista creada por el Estado social es más extendida y significativa en las sociedades del centro que en las sociedades de la periferia, si bien en la actual coyuntura estas estatalidades están experimentando un proceso de retracción mundial.

En cuanto a los espacios naturales no capitalistas disponibles en el Centro y en la periferia global, se observan grandes transformaciones en las últimas décadas. En América Latina se viene constatando la extensión de las "fronteras agropecuarias" (Viglizzo y Jobbagy, 2014; Carrasco, Sánchez y Tamagno, 2012; Soto, 2013; Iñigo Carrera, 2017; Roccatagliata, 1988) y de las "fronteras mineras" (Gutman, 2013; OCMAL, 2014) a un ritmo vertiginoso. De persistir la dirección y el ritmo de esta tendencia expansiva el continente tendrá, en un mediano plazo, menos superficies geográficas y naturales "externas" al sistema capitalista que los propios ecosistemas del Centro. La magnitud de este proceso periférico deja en evidencia un diferencial histórico de conservación de recursos naturales a favor de los territorios del Norte Global. En sus formas económicas actuales, la expansión de las fronteras agropecuarias y mineras en el Sur Global tiende a reforzar los procesos de integración regional desde arriba o de división internacional del trabajo capitalista impuesta desde el Centro. Aquí queda por investigar en qué medida los territorios nacionales en América Latina podrían estar transitando hacia nuevas matrices de dependencia capitalista. Ello podría estar ocurriendo, por ejemplo, si se comprueba que la reducción en curso de la diversidad de las economías primarizadas de la periferia hacia modalidades de mono-cultivo de exportación tiende a reducir sensiblemente la soberanía y la seguridad alimentaria de los países periféricos ${ }^{12}$. En el caso de la Argentina ello podría estar ocurriendo a partir de la expansión del modelo de agronegocio sojero ${ }^{13}$. En

12 Según los informes de la FAO, la seguridad alimentaria requiere el cumplimiento de, por lo menos, cuatro condiciones: i) Una oferta y disponibilidad de alimentos adecuadas; ii) La estabilidad de la oferta sin fluctuaciones ni escasez en función de la estación del año; iii) El acceso directo a los alimentos o la capacidad para adquirirlos; iv) La buena calidad e inocuidad de los alimentos. Según el propio organismo mencionado en el Norte Global los tres primeros puntos estarían por el momento garantizados, no así en América Latina (ver FAO, 2010).

13 Ver entre otros Reboratti, 2010; Teubal, 2002 y 2006. síntesis, ya sea por debilidad de la intervención estatal y/o por sobre-explotación capitalista de la naturaleza económicamente valiosa, es probable que América latina se esté proyectando como un territorio más plenamente integrado al sistema de valorización capitalista que el Centro global.

La única espacialidad no capitalista con la que contaría América Latina en mayor magnitud que el Centro Global es precisamente aquella demarcada por las masas de individuos sumergidos. El continente cuenta desde siempre con una integración parcial y más precaria del territorio social al sistema capitalista. Tal proliferación da cuenta del desenvolvimiento dramático de una sociedad de individuos excluidos no ya del mercado de trabajo asalariado sino del mercado de consumo capitalista de supervivencia. En cualquier caso, a diferencia de la visión de Dörre, desde el SI no se puede pensar la relación entre los procesos de expansión y de exteriorización capitalista sin establecer una diferenciación sustantiva entre territorios naturales y territorios sociales. Si los territorios naturales de América Latina experimentan un proceso de creciente y plena integración en el proceso valorización mundial del capital, simultáneamente se está acentuando un proceso de desintegración capitalista de los pequeños territorios sociales y de los territorios sociales de abajo. Pero no se trata de una desintegración capitalista de la clase orgánica periférica como un todo, del entramado económico nacional, si no de sus eslabones más débiles. Esta desintegración masiva de la sociedad de consumo se expresa centralmente a partir de dos formas: i) como desintegración de la sociedad rural aún existente y su reintegración precaria en la sociedad urbana en expansión ${ }^{14}$, y ii) como desintegración capitalista de una fracción del territorio social de abajo de los centros urbanos en América Latina. La primera modalidad se asocia con un proceso de mudanza a gran escala por necesidades de supervivencia y por búsqueda de oportunidades económicas desde zonas rurales y pequeñas poblaciones hacia las ciudades grandes y medianas. En algunos países de la región, entre ellos la Argentina, la sociedad rural se va retrayendo dramáticamente -hasta el punto de desaparecer en algunos casos- a medida que avanza a grandes pasos la

14 Con integración precaria me refiero aquí a un tipo de integración que ocurre mayoritariamente por la delgada línea del consumo de supervivencia y no por la vía de la sociedad del trabajo formal. 
concentración del negocio agro-industrial en la región. Este proceso contemporáneo está creando lo que algunos especialistas llaman una "agricultura sin agricultores"15. Respecto a la segunda forma de desintegración, las fracciones excluidas del consumo necesario para la supervivencia se corresponden en buena medida con lo que se conoce como "pobreza extrema" en el lenguaje de los organismos internacionales. Según el último informe de la CEPAL la pobreza extrema en 2018 alcanzó al 10,2\% de la población de la región, unas 62 millones de personas, y aproximadamente al 3\% de la población argentina. Para ambos arreglos espaciales, el regional y el nacional, se trata del porcentaje más alto desde 2008 (CEPAL, 2018). Para Europa, en cambio, desde fines de la segunda guerra la pobreza extrema es prácticamente inexistente, aún en los países más empobrecidos del Sur.

En resumidas cuentas, si para Dörre el "afuera” no capitalista que crea el capitalismo a partir de sus fuerzas expulsivas se identifica paradigmáticamente con el mundo dinámico de la desocupación formal ${ }^{16}$, para el SI el piso social de la exclusión es mucho más bajo, trasladándose paradigmáticamente a las situaciones de extrema pobreza en las cuales comienzan a fallar seriamente las tácticas de supervivencia de los individuos. La población en condición de extrema pobreza incluso no logra consolidar su pertenencia a ninguna de las clases moleculares bajas. Se convierte en un remanente poblacional perseguido por el hambre y entregado a una lucha sórdida por la supervivencia en el sótano de

15 Los números que ofrece Teubal respecto a la Argentina son bien elocuentes: "entre los censos de 1960 y 1988 desaparecieron 51.000 explotaciones agropecuarias, 1.800 por año. Entre los censos de 1988 y 2002 -en plena era neoliberal- desaparecieron 87.000 explotaciones agropecuarias, esto es, 6.263 por año. Y las que desaparecieron fueron fundamentalmente las de menos de 200 hectáreas (75.293 explotaciones). En cambio, aumentaron las de más de 500 hectáreas, particularmente las del estrato de entre 1.000 a 2.500" (Teubal, 2006). De este modo, el especialista va a señalar el agro argentino se fue transformando a paso acelerado en una agricultura sin agricultores, ya que las explotaciones que desaparecieron fueron principalmente las medianas y las pequeñas.

16 Lo que en términos exactos dirá Dörre es que el funcionamiento del mecanismo del ejército de reserva significa la fabricación continua de un "afuera" en la forma de mano de obra prescindible, que en un determinado momento puede ser simplemente excluida del sistema para tenerla a disposición con el fin de acumular en un momento futuro. El sociólogo alemán va a afirmar que "adentro" hay explotación, es decir, la apropiación privada de una plusvalía producida colectivamente, mientras que "afuera" está la reducción de ingresos y de condiciones de vida bajo los estándares aceptados de clase, la sobrexplotación, el uso de actividades de reproducción y cuidado de forma gratuita y en casos extremos el deterioro total de capacidad laboral (Dörre, 2016a, p. 28). la sociedad de clases de los países periféricos ${ }^{17}$. Y es precisamente este sub-mundo social arrasado el que se erige como un espacio social no capitalista producido por el propio sistema inter-capitalista. Será a partir de este territorio de miseria social en permanente expansión y retracción, y no precisamente a partir del accionar estatal latinoamericano o del reservorio de tierras vírgenes por explotar, que se crea a partir de un proceso de expulsión desde arriba el territorio social no capitalista en América Latina. Desde la óptica del SI, es posible observar que si la territorialidad "exterior" no capitalista que acompaña el desarrollo capitalista hacia adentro de Europa la crea el Estado a partir de sus mallas de protección y de integración socioeconómica, en América Latina la crean los actores centrales del mercado capitalista a partir de la generación de una "población excedente absoluta"18. Esta última llega al límite de desconectarse de los ingresos que podrían generarse a través de la mendicidad o del micro-delito.

\section{Conclusión: del sistema capitalista al juego de apropiación mundial}

El supuesto de la doble estructuración del capitalismo sienta las bases para el desarrollo de la perspectiva del sistema inter-capital (SI). Este nuevo dispositivo pretende operar como reemplazo del concepto marxiano de modo de producción capitalista. En el presente trabajo me ocupó de introducir algunas de las modificaciones que produce esta nueva perspectiva teórica al encontrarse con una de las visiones críticas del capitalismo más vigorosas en la actualidad. Me refiero a la teoría del Landhname capitalista del sociólogo alemán Klaus Dörre. Desde la visión del SI, la perspectiva del sociólogo alemán ofrece una teoría de la estructuración simple del capitalismo, con proyección global y sensibilidad mundial. Cuando digo que se trata de una teoría de la estructuración simple quiero indicar que su visión de la dinámica

17 A modo de indicador, según un reciente informe del Observatorio de la Deuda Social de la Universidad Católica Argentina (UCA), en el país el riesgo alimentario en la infancia se incrementó en el último período interanual, 2017-2018, en un 35 por ciento, 7 puntos más que en 2010. Según el informe en cuestión tres de cada diez chicos y chicas pertenece a hogares en los cuales el acceso a los alimentos se complicó en 2018. De esos niños, el 13 por ciento pasó hambre durante dicho año. Según el informe 1.6 millones de niños y adolescentes en la Argentina realiza menos de cuatro comidas diarias (ver UCA, 2019).

18 El término le corresponde a García Argumedo (2011). 
total de clase se ajusta a la acepción marxiana de una dinámica entre clases capitalistas y clases trabajadoras en un plano principalmente nacional. $\mathrm{Al}$ señalar que su teoría tiene proyección global quiero indicar que el autor parte del análisis del funcionamiento del capitalismo europeo, principalmente el alemán, para ensayar a partir de ahí una explicación del movimiento del capitalismo a nivel global. Finalmente, cuando indico que su teoría tiene sensibilidad mundial me refiero en particular al reconocimiento por parte del autor de la existencia a la vez diferenciada y erosionada de la periferia global en su visión de la dinámica capitalista. De este modo, si bien la teoría de Landhname capitalista demuestra una sensibilidad notable con las realidades del Sur Global, desde el SI tal sensibilidad se vería enriquecida si lograse brindar una mayor atención teórica a la relación centroperiferia. Antes que incompatibilidades sustantivas entre el concepto de Landnahme capitalista y la visión del sistema inter-capital, se observa el involucramiento de dos marcos mundiales diferentes y potencialmente complementarios: el de una mundialización marxista reflexiva, de nuevo cuño, y el de una mundialización ampliada de las economías capitalistas. En cualquier caso, es necesario no perder de vista que el sistema intercapitalista es el primus inter pares de un conjunto de cinco sub-sistemas que componen el juego de apropiación mundial como sistema mundial. Los otros cuatro son el sistema inter-estatal, el sistema inter-medial, el sistema patriarcal y el sistema inter-natural.

\section{Bibliografía}

Amin, S. (1979). Classe et Nation. Dans l' histoire et la crise contemporaine. Paris: Les Editions de Minuit

Argumedo, A. (1992). Los silencios y las voces en América Latina: notas sobre el pensamiento nacional y popular. Buenos Aires: Pensamiento Nacional, 2011.

Balibar, E.; Wallerstein, I. (1988). Raza, nación y clase. Madrid: IEPALA.

Cardoso, F.H. (1965). Análisis sociológicos del desarrollo económico. Revista Latinoamericana de Sociología, No 71, vol. 2., pp. 178-199

Cardoso, F.; Faletto, E. (1973). Dependencia y desarrollo en América Latina. Buenos Aires: Siglo XXI, 1977.

Carrasco, A.; Sánchez, N.; Tamagno, L. (2012). Modelo agrícola e impacto socio-ambiental en la Argentina: monocultivo y agronegocios. AUGM-Comité de Medio Ambiente.

CEPAL (2019), Panorama Social de América Latina 2018. LC/PUB.2019/3-P. Santiago de Chile.

Di Tella, T. (1998). Historia social de la Argentina contemporánea. Buenos Aires: Troquel.
Dörre, K. (2012). Die neue Landnahme. Dynamiken und Grenzen des Finanzmarktkapitalismus. In: Klaus Dörre, Stephan Lessenich e Hartmut Rosa (2012). Soziologie - Kapitalismus - Kritik. Frankfurt: Suhrkamp, pp. 21-86.

Dörre, K. (2014). The German Job Miracle. A Model for Europe? Brussels: RLS

Dörre, K (2016a). Capitalismo, Landnahme y regímenes sociales de tiempo: un panorama general. Pléyade. Revista de humanidades y ciencias sociales. Núm. 18, julio-diciembre 2016, pp.25-54.

Dörre, K. (2016b). Capitalist Landnahme - Consequences in Germany and Europe and Possible Alternatives. Papers presented at the 3rd ISA Forum 'The Futures We Want', Vienna, July 2016

Dörre, K (2018). Democracy, not Capitalism - or: Expropriate Zuckerberg! Non published Working Paper.

Dörre, K. (2019). Take Back Control!’ Marx, Polanyi and Right-Wing Populist Revolt. Österreichische Zeitschrift für Soziologie, 44, pp.225-243

FAO (2010). Politicas de seguridad e Inocuidad y Calidad Alimentaria en América Latina y el Caribe. Santiago de Chile: FAO-RLC.

Gutman, N. (2013). Argentina en la frontera minera. Buenos Aires: Ediciones del CCC-CEMOP.

Haya de la Torre, V. (1935). El antiimperialismo y el APRA. Lima: Fondo Editorial del Congreso del Perú, 2010.

Hobsbawm, E. (2015). La era de la revolución <1789-1848>, la era del capital $<1848-1875>$, la era del imperio <1875-1914>. Buenos Aires: Crítica.

Innis, H. (1948). Great Britain, The United States and Canada. En: Essays in Canadian Economic History. Toronto: University of Toronto Press, 1956, 407450 .

Iñigo Carrera, V. (2017). Frontera agropecuaria y territorio en el noreste de Argentina: su avance y ordenamiento en la provincia de Formosa. Revista GeoPantanal, 22, Enero-Junio, 55-72.

Kautsky, K. (1907). Socialism and Colonial Policy. En: https:/www.marxists. org/archive/kautsky/1907/colonial/index.htm

List, F. (1841). El Sistema Nacional de Economía Política. México: FCE, 1942

Luxemburgo, R. (1913). La acumulación del capital. Ciudad de México: Grijalbo, 1967.

Marx, K. (1853). El 18 brumario de Luis Bonaparte. En: Marx, K; Engels, F. Obras escogidas. Tomo 1, Moscú: Progreso, 1981, 404-498.

OCMAL (2014). Conflictos Mineros en América Latina: Extracción, Saqueo y Agresión. Estado de situación en 2014. Url: https://www.ocmal.org/ conflictos-mineros-en-america-latina-extraccion-saqueo-y-agresion-estadode-situacion-en-2014/

Prebisch, R. (1976). A critique of peripheral capitalism. CEPAL Review, Num.1, 1976. [Versión ampliada en español: (1981). El capitalismo periférico. Crisis y transformación. México: Fondo de Cultura Económica.

Prebisch, R. (1985). The Latin American periphery in the global crisis of capitalism. CEPAL Review, 26, 63-88.

Ramos, J.A. (1968). Historia de la Nación Latinoamericana. Buenos Aires: Continente.

Reboratti, C. (2010), Un mar de soja: la nueva agricultura en Argentina y sus consecuencias. Revista de Geografía Norte Grande, 45, mayo, 63-76.

Ribeiro, D. (1968). El proceso civilizatorio. Etapas de la evolución socio-cultural. Universidad Central de Venezuela: Ediciones de la Biblioteca.

Roccatagliata, J. (1988). (Coord). La Argentina. Geografía general y los marcos regionales. Buenos Aires: Planeta. 
Encuentros / El sistema inter-capital: hacia una mundialización ampliada de la economía capitalista

Scalabrini Ortiz, R. (1940). Política británica en el Río de la Plata. Barcelona: Plus Ultra, 2001

Soto, G. (2013). Expansión de la frontera agrícola en el norte de Córdoba. Transformaciones productivas, naturales y sociales. Las Voces del Fenix, Año4, 28, Septiembre 2013, 32-39.

Streeck, W. (2013). Comprando tiempo. La crisis pospuesta del capitalismo democrático. Buenos Aires: Katz Editores, 2016.

Teubal, M.; Rodríguez, J. (2002). Agro y alimentos en la globalización. Una perspectiva crítica. Buenos Aires: La Colmena.

Teubal, M. (2006). Expansión del modelo sojero en la Argentina. De la producción de alimentos a los commodities. Realidad Económica, 220, mayojunio.

Torres, E; Borrastero, C. (2019). Capitalism and the State in Latin America: Concentration of Power, Social Inequality and Environmental Depletion. En: Bada, X; Rivera-Sánchez, L. (eds). The Oxford Handbook of Latin American Sociology. New York: Oxford University Press, 2020 (En prensa).

Torres, E. (2019). Hacia una nueva teoría de las clases sociales: la dialéctica de lo orgánico y lo molecular. En: Torres, Esteban; Goncalvez, Guilherme (eds). Hacia una nueva sociología del capitalismo: Un diálogo con Alemania. Buenos Aires-Jena: CLACSO-Universität Jena, 230-258.

UCA (2019). Infancias. Progresos y retrocesos en clave de desigualdad. Informe del Observatorio de la Deuda Social de la Universidad Católica Argentina. Url: http://uca.edu.ar/es/observatorio-de-la-deuda-social-argentina

Viglizzo, E.; Jobbág, E. (eds) (2010). Expansión de la Frontera Agropecuaria en Argentina y su Impacto Ecológico-Ambiental. Buenos Aires: Instituto Nacional de Tecnología Agropecaria. 